ARTICLE

https://doi.org/10.1057/s41599-019-0273-2

\title{
Veterinarian 'responsibility': conflicts of definition and appropriation surrounding the public problem of antimicrobial resistance in France
}

Nicolas Fortané 1,2

\begin{abstract}
Over the past decade, veterinarians have been accused of being largely responsible for the overuse of antibiotics in livestock farming. Building on Gusfield's theoretical perspective, I analyse how AMR can be conceived as a public problem and show how the French veterinary profession has been able to reframe it in such a way that veterinarians are no longer perceived as a threat but instead as protectors of public health. Based on interviews with political stakeholders and veterinary practitioners, as well as on a survey of the veterinary press, this article interprets the controversies that structure the AMR problem as conflicts of definition and appropriation with regard to the legitimate uses of antibiotics. Veterinarians have had to make significant compromises in order to reframe their responsibility and not lose control over the prescription and sale of antibiotics. This dynamic is the result of a three-stage process: firstly, veterinarian responsibility was conceived as a form of ownership where their authority to define the legitimate use of antibiotics was not contested; secondly, it was deemed to be a form of guilt whereby they were dispossessed of their legitimacy and capacity to act; thirdly, it was framed as a form of accountability where they were able to demonstrate their role as public health guardians. During this most recent stage - which corresponds to the present framework of the AMR problem - veterinarians have had to accept that the control and definition of legitimate uses of antibiotics needs to be distributed among a wider range of actors than was the case in the past.
\end{abstract}

\footnotetext{
${ }^{1}$ Institut National de la Recherche Agronomique, IRISSO (CNRS, INRA, Paris-Dauphine, PSL Research University), Paris, France. ${ }^{2}$ Department of Global Health and Development, Faculty of Public Health and Policy, London School of Hygiene and Tropical Medicine, London, UK. Correspondence and requests for materials should be addressed to N.F. (email: nicolas.fortane@inra.fr)
} 


\section{Introduction}

he problem of antimicrobial resistance (AMR) is particularly interesting because it is highly fragmented between actors competing for its ownership, making it relatively plastic and subject to many controversies with regard to its modalities of regulation (Bud, 2007; Podolsky, 2015, 2018). One specific facet of this problem is particularly affected by these conflicts of definition and appropriation: the agricultural sector. Indeed, the use of antibiotics in livestock farming is regularly accused of being at the root of the development of resistant bacteria that are dangerous to human health. Ever since antibiotics began to be widely used in agriculture in the late 1940s, the problem of AMR in livestock farming has been the subject of several episodes of publicity, the different framings of which have led to a wide range of management methods and measures of control, depending on the historical and geographical contexts (Finlay and Marcus, 2016; Begemann et al., 2018; Kirchhelle, 2018). For example, in Europe from the mid-1990s to around the mid-2000s, one construction of the problem that mainly highlighted the risks posed by agricultural uses of antibiotics led to the ban on growth promoters in 2006. More recently, there have been controversies about the status of colistin, an antibiotic that is commonly used in agriculture in LMICs but that human medicine would like to classify as a last-resort antibiotic and reserved for use by doctors.

This paper aims to analyse how AMR issues are framed, i.e., how definition and appropriation conflicts concerning the legitimate use of antibiotics involve a large range of actors competing for the control of the prescription, sale and use of antimicrobials. It focuses on the veterinary profession and the controversies that arose as from the late 2000's regarding prescription veterinary antibiotics (i.e., antibiotics used for preventive or therapeutic purposes) which were accused of promoting the spread of resistant bacteria in food and the environment. Unlike the growthpromoter crisis where it was essentially the livestock industry that was under the spotlight (since this use of antibiotics did not require veterinary prescription), it was the veterinary profession that found itself at the heart of this new controversy. It was blamed for the misuse of antibiotics and accused of overprescription for economic purposes. Its legitimacy was then strongly contested. As was the case in many countries, at a European level this reformulation of the AMR problem led to the adoption of measures aiming to regulate the conditions under which veterinary medicines are prescribed, sold and used. However, within a few years, the veterinary profession finally succeeded in re-appropriating the AMR problem and rebuilding a definition that places it in a position of guarantor of the responsible use of antibiotics in livestock farming. This shift in the way veterinarian responsibility has been framed is the result of a three-stage process (ownership, guilt and accountability) that this paper aims to analyse within the framework of the case in France.

I articulate here the data of three different studies which have been carried out over the years. Firstly, I use the results of a study (2013-2015) that examines how the veterinary profession contributed to the French AMR policy, based on a press analysis on how AMR was treated in the main veterinary professional journal from 2006 to 2014 (La semaine vétérinaire) and on 12 semistructured interviews with political stakeholders (representatives of veterinary and medical organizations, and policy-makers from the ministries of Health and Agriculture). Secondly, I conducted an ethnographic analysis (2012-2014) of a veterinary expert committee of the French Agency for Food Safety (Anses) whose objective was to produce standards and guidelines for the appropriate use of antimicrobials in livestock. This study gathers about $100 \mathrm{~h}$ of observation and 9 semi-structured interviews which were representative of the 26 veterinary scientists and practitioners composing this committee. Thirdly, I use the results of 21 semi-structured interviews with veterinarians from the pig and poultry sectors, carried out for a research on the strategies developed by farmers and veterinary practitioners to reduce antimicrobial use in livestock in France (2014-2016). Gathering the data of these three researches enabled me to grasp the overall framing process of veterinarian responsibility for the AMR problem, from the perspective of both stakeholders and field actors ${ }^{1}$.

\section{AMR as a public problem}

The sequence which is analysed here allows us to understand to what extent it is heuristic to apprehend AMR as a public problem, in Gusfield's sense, in other words as an issue that is the product of a social construction articulating three levels of framing: its ownership (the actors who claim the legitimacy to define and name the problem), its causal responsibility (the establishment of causal factors to explain the problem's occurrence) and its political responsibility (the designation of the actors required to take charge of the problem) (Gusfield, 1981).

The sociology of public problems allows us to consider the framing of public policy, and the role of ideas in political and institutional change. The notion of 'framework' has been addressed by the literature through a variety of concepts, be it a policy paradigm (Hall, 1993), a belief system (Sabatier, 1988), a policy image (Baumgartner and Jones, 1993) or a causal story (Stone, 1989). The relevance of Gusfield's approach is that it can be articulated both with political science research that emphasizes the strategies and mobilizations of actors in agenda-setting processes, whether we are talking about an advocacy coalition (Sabatier and Jenkins-Smith, 1993), a policy community or an issue network (March and Rhodes, 1992), and the sociology of collective action and social movements that provides a thorough analysis of the framing processes on which these mobilizations are based (Snow et al., 1986; Snow and Benford, 1988; Benford and Snow, 2000). Analysing the construction of a public problem and its successive reformulations thus makes it possible to understand how actors compete to define legitimate norms (e.g., the 'proper' use of antibiotics) and support ways of controlling the application of these norms (e.g., prohibiting such use in a given context). As Gusfield says, framing a problem therefore consists in defining a certain number of responsibilities: that of appropriating the problem (ownership), that of attributing its causality or even guilt (causal responsibility) and that of defining its accountability, solutions and forms of management (political responsibility). In the context of recent controversies over the use of antibiotics in animal farming, the veterinary profession has gone through these different forms of responsibility with regard to the AMR problem.

But in a context where the main actors involved are professional groups defending their territory, Gusfield's sociology also has the advantage of being able to link up with Abbott's. Indeed, the conflicts surrounding the definition and appropriation of the AMR problem (defining the legitimate uses of antibiotics) are also jurisdictional conflicts (Abbott, 1986, 1988) concerning the control of a professional activity (prescribing, selling and using drugs). So when veterinarians risk losing the right to use a particular antibiotic to doctors, because a certain framework considers that this use bears causal responsibility for the AMR problem, it is not just a professional practice that is threatened but in fact a monopoly that is historically guaranteed by the State and on which the veterinary profession has built its legitimacy. Some 'publics' (Dewey, 1927; Cefaï and Terzi, 2012) of the AMR problem are therefore easy to mobilize, because they are professional groups that have jurisdiction over certain uses of drugs (particularly sale and prescription) and have support from the 
political and administrative authorities to defend it (Abbott, 2005). By linking Gusfield and Abbott in this way, I consider that conflicts concerning the framing of the AMR problem and policy are also conflicts that concern the control and definition of the legitimate uses of antibiotics.

The way veterinarian responsibility for the AMR problem has shifted over recent years in France perfectly illustrates these theoretical elements. Indeed, if the veterinary profession now appears to be a major actor in preserving the effectiveness of antibiotics and guaranteeing their 'responsible' use, this has only been at the cost of a significant reformulation of the AMR problem. This paper analyses the three stages of this process. Firstly, I show how the issue of prescription veterinary antibiotics was governed prior to the re-emergence of the AMR problem in the late 2000s and how this mode of regulation, which might be described as 'discreet and confined management' (Gilbert and Henry, 2012), was preventing any contestation of veterinary ownership (and thus framing) of the problem. At that time, the responsibility of veterinarians can be described as undisputed ownership of the definition and control of the legitimate use of antibiotics in livestock. Secondly, I analyse how a competing framing of this issue arose around 2010, depriving veterinarians of this ownership. A new version of the AMR problem emerged, establishing the idea that veterinary use of antibiotics was the main cause of the spread of resistant bacteria in food and the environment. At that moment in time, the responsibility of veterinarians shifted towards a form of guilt and the profession was on the point of losing an important share of its jurisdiction over medicines. Thirdly, I explain how veterinarians have finally been able to counter this framing and build an alternative scheme where they are no longer a threat to public health, but instead appear to be its indispensable protector. In this sequence which still characterizes the way we view the AMR problem today, the responsibility of veterinarians is framed as a kind of accountability for the 'good' or 'appropriate' (in other words, legitimate) use of antibiotics. I conclude by discussing how the different framings of the AMR problem have endowed veterinarian responsibility with different meanings (ownership, guilt and accountability), and how these AMR frames ring professional jurisdictions into play with regard to the definition and control of the legitimate use of antibiotics.

\section{The regulation of the veterinary drug market, an issue confined to the agricultural sector: the 'responsibility- ownership' of veterinarians}

In France, according to historian Hubscher (1999), the 1975 Act on veterinary pharmacy marks an important date in the process of professionalising veterinarians. It provides them with a monopoly on medicine control, by excluding the latest 'empirics' (peddlers, farriers, healers, etc.) from the animal care market. In a way, this law completes the professional jurisdiction of veterinarians over animal health (even though it can still be challenged during crises (Bonnaud and Fortané, 2018)), putting an end to a long historical process that began in the 19th century (Berdah, 2010, 2012). It is often considered that veterinarians have had a dual monopoly on medicines since 1975: not only on their prescription but also on their delivery. In reality, the latter is divided between three beneficiaries who are supposed to share the sale of pharmaceuticals. But the way the veterinary drug market has been structured for approximately 40 years has helped to place one particular category of drugs at the heart of the economic model of veterinary medicine: antibiotics.

The veterinary drug market as defined by the 1975 Act can be described as follows. The farmer calls upon his veterinarian when a health problem arises in his herd that he is unable to solve by himself, for example by changing his animal feed or other aspects of his livestock management practices. The veterinarian then intervenes by making a medical diagnosis and prescribing appropriate therapeutic treatment. The prescription allows the farmer to buy the drug from the supplier of his choice, whether it is his veterinarian, a competing veterinarian or pharmacist or possibly his cooperative. Indeed, the 1975 Act gives agricultural cooperatives the right (under certain conditions) to hold and sell pharmaceuticals named in a 'positive list', i.e., medicines for preventive or zootechnical purposes, including vaccines, hormones or anthelmintics. However, while the delivery of pharmaceuticals is in theory divided between three beneficiaries, pharmacists actually capture only a tiny share of the market for prescription veterinary drugs, unlike the veterinarians themselves and the many licensed cooperatives, particularly in the poultry and pig production sectors (Delomenie et al., 2002).

This situation is the consequence of the practices that were introduced following the 1975 Act, which finally led to the development of a 'captive' market in which the monopoly on prescription drugs gave veterinarians a quasi-monopoly over their delivery, in other words over their sale. Indeed, veterinarians gradually abandoned the invoicing of medical acts and used drug supply to capture their clients. While farmers can theoretically purchase pharmaceuticals wherever they want, they almost always end up buying drugs from their veterinary practitioner because they will not be charged for any other services (such as diagnosis, advice or prescription). While, until the early 1980s, farm animal veterinarians' incomes were relatively diversified (farm visits or certain surgical acts were charged to farmers (Buffetaut and Gourlet-Fleury, 2001)), drug sales have now become the main share of the income structure of farm animal veterinarians (60-90\% of their turnover) (Dahan et al., 2013) ${ }^{2}$.

While pharmacists were quickly excluded from the veterinary drug market, this is not the case for licensed cooperatives. The latter have a close relationship with farmers (in particular via the technicians who visit farms much more frequently than veterinarians) so that they can force farmers to buy a wide range of agricultural inputs via bills of specifications or sometimes more informal agreements. As a result, cooperatives have also managed to capture a significant share of the veterinary drug market - at least regarding pharmaceuticals included in the 'positive list'. However, until recently, cooperatives had also managed to take over part of the sale of curative medicines, bypassing regulations by employing veterinarians and thus recovering their right to sell this category of pharmaceuticals (Dahan et al., 2013). So in industrial sectors in particular, cooperatives and their employed veterinarians have gradually succeeded in forming an alliance enabling them to capture a very large share of the drug market, to the detriment of 'small' independent veterinary practices and pharmacists. A veterinarian from the pig industry describes this process:

In your opinion, are there key moments, or key dates, when significant changes in laws or regulations appeared and favoured this system?

It was in 1975, when there was the positive list and the cooperatives started selling everything. (...) They received authorization, supposedly to do sanitary work, but in fact to make money. And the medicines were to pay the technicians. I worked for a producers' organization, I worked for 30 years, and the boss told me: 'we need the money from the medicines to run the business'. It's financial. (...) So they hired vets. They wanted a captive market for the cooperatives, so they hired vets. (...) And then they said to themselves: 'we have vets, why should we 
call other independent vets for the drugs'. So they put it all together and sold it all.

And the incomes from the drug sales went directly to the cooperative? The veterinarian was an employee, but he had his own pharmacy. So did he make any profit?

He didn't even have a pharmacy, the cooperative sold everything and it was them that put everything in their own pocket.

But using the veterinarian's name for everything that wasn't on the positive list?

Yes, in fact, they have extended their beneficiary rights. They were authorized for the positive list but they decided they were also allowed to sell the full range of veterinary pharmaceuticals.

And the vets, they were just getting their salary, without any added-value for the prescription-sale of antibiotics?

No, they weren't earning more for that. They were just putting in their working hours and then they were happy. They preferred to be employees. They preferred to be employees, to have a pension. They were quite well paid. (...) And the independent vets suffered from that ${ }^{3}$.

During the 2000s, veterinarians marginalized in the drug market (i.e., veterinarians not linked to cooperatives and whose clientele was declining, or 'small' practices that could not be competitive on drug prices because of low sales volumes) criticized the 'business-oriented' practices of their peers. The State intervened and proposed two amendments to the 1975 Act. Firstly, the Riaucourt judgment made it impossible for a cooperative to employ a veterinarian, thus putting an end not only to an illegal practice (selling medicines not included in the positive list) but also in principle promoting more balanced competition within the veterinary profession by preventing clientele capture (Guillemot and Vandaële, 2009) ${ }^{4}$. Secondly, under certain conditions the 'prescription/delivery' decree authorised prescription without clinical examination, allowing medicines to be dispensed without having to visit the farm ${ }^{5}$. This measure, which had been demanded for several years by veterinarians and farmers alike, tends to give farmers a certain degree of autonomy in the health management of their herds. It thus frees veterinarians from timeconsuming tasks that provide no direct remuneration (at least tasks which were not economically constructed as such), allowing them to become health advisers rather than clinicians per se.

But this structuring of the veterinary drug market since the 1980s has had at least one essential consequence: the sale of curative drugs, of which antibiotics are the main category, has become the main source of income for veterinarians, at least in farm animal practice. In other words, veterinary activity is based on an economic model that places antibiotics at its core, even though the expertise and services that veterinarians offer to their clients are much more diversified than the sole delivery of medicines (diagnosis, therapeutics, technical advice on biosecurity, feeding, building management, etc.). Moreover, the issue of prescription and delivery of veterinary drugs was managed by a relatively small and discreet 'policy community' (Marsh and Rhodes, 1992) in confined political and administrative areas (Gilbert and Henry, 2012). This veterinary policy community was composed by the veterinary profession, State veterinary services and agricultural stakeholders, which were owning, framing and governing the issue of veterinary drugs regulation in a way that almost never gave rise to public debates. In a sense, this policy structure can be compared to what Abbott calls a "hinge" (Abbott, 2005), that is to say an alliance between a profession and an administration through which a professional jurisdiction is guaranteed by the State. The 1975 Act played a major role in the establishment of the veterinary monopoly over medicine prescription and sales, and thus allowed the veterinary profession to remain unchallenged for more than 30 years with regard to how it framed and managed issues relating to antimicrobial use in livestock. Veterinarian responsibility for AMR might therefore be described as a form of uncontested ownership: antibiotic use is not deemed to be a problem and the policy community maintains its dominant hold over policy-making. The re-emergence of AMR controversies at the end of the 2000's nevertheless destabilized this veterinary 'hinge' and led to an era of definition, appropriation and jurisdiction conflicts over the AMR problem.

\section{Accusation and contestation of the problem ownership: the 'responsibility-guilt' of veterinarians}

Although the AMR problem was widely publicized in the 1990s and early 2000s, prescription veterinary antibiotics were not really affected. Indeed, only agricultural uses of antibiotics as growth promoters, which did not require veterinary prescription, were the subject of intense controversies, before being banned in Europe (Kirchhelle, 2018). Issues relating to the regulation of veterinary uses of antibiotics (conditions of prescription, sale and use) have thus remained relatively undifferentiated in debates on veterinary pharmaceuticals and measures concerning the veterinary drug market. In France, the definition of veterinary uses of antibiotics therefore remained the ownership of the veterinary policy community that had been established in the wake of the 1975 Act. But the 2007 'prescription-delivery' decree changed the situation. It provided an opportunity for actors outside this confined public policy network to challenge the existing structure of the drug market by establishing a direct link between veterinary practices regarding drug sales and prescription and the AMR problem.

Indeed, the possibility offered to veterinarians to prescribe medicines without clinical examinations opened a 'policy window' (Kingdon, 1984) ${ }^{6}$ for a competing professional group - pharmacists - to challenge the legitimacy of the veterinary drug legislation, and therefore of veterinary jurisdiction over medicines. At the end of the 2000s, after the ban on growth promoters, the issue of antibiotic use in livestock farming became relatively invisible in the French public space. But the problem for human medicine started to be the subject of increased debate, as the number of antibiotic prescriptions tended to rise (following a sharp decline at the beginning of the decade) (Crémieux, 2016). Political actors thus began to address the issue once again, in the wake of the first European Antibiotic Resistance Day in 2008. A coalition of human health stakeholders (led by pharmacists, but also doctors and the health administration) then managed to bring the issue of veterinary uses back under the spotlight, accusing veterinarians of being equally, if not mainly, responsible for the spread of resistant bacteria that are dangerous for human health. This sequence is fairly representative of how an external policy network can try to appropriate (i.e., take ownership of) a public problem and build an alternative framing in order to promote other solutions and ways of governing a specific issue. In this sense, the confined policy community which was in charge of veterinary drug regulation for decades lost its legitimacy and became an issue network (Marsh and Rhodes, 1992), where a wide range of actors are competing for the ownership of a public problem and its related policy. This situation is quite typical of moments of crisis in animal health 
policies (Bonnaud and Fortané, 2016), as has been shown in cases such as the foot-and-mouth disease crisis in the UK (Wilkinson et al., 2010) or the bluetongue disease crisis in France (Ollivier, 2013). In the case of the AMR problem, the first step of this new sequence where an issue network replaces a policy community is somewhat dominated by the advocacy coalition (Sabatier and Jenkins-Smith, 1993) formed by human health stakeholders.

The framework built by this coalition was based on a fairly simple argument: since veterinarians have a (de facto) twofold monopoly on the prescription and delivery of antibiotics, they are in a situation of 'professional conflict of interest' that encourages them to overprescribe pharmaceuticals in order to increase their income. The 'causal story' (Stone, 1989) of this framework is pretty clear. Indeed, we have seen that the structure of the veterinary drug market and the farm animal care market is based on an economic model that puts the sale of drugs as the main source of incomes for veterinary practices. In addition, pharmacists are excluded from this market even though they are legally eligible for veterinary medicine delivery. This configuration, combined with the re-emergence of the AMR problem in the public space, has allowed this coalition of human health actors to build a framework that makes veterinarians the main stakeholder responsible (in the sense of guilty) for the spread of resistant bacteria. The veterinary profession (and more broadly, the veterinary policy community) was thus deprived of its historical autonomy over the definition and management of drug-related issues, this dis-appropriation taking place through a form of politicization of the AMR problem - a typical process that enables external and resource-lacking policy networks to challenge previous established frameworks (Rochefort and Cobb, 1994).

This politicization can be clearly observed in the way the human health coalition managed to reframe the AMR problem and show how framing processes are related to actor mobilization (Benford and Snow, 2000). Following this denunciation of the veterinarians' 'conflict of interest', the entire public debate focused on the twofold veterinary monopoly on prescription and delivery. One key word characterizes the pervasiveness of this framework: decoupling. This was the solution put forward by the human health stakeholders, consisting in aligning the veterinary drug legislation with the human medicine model. This would have meant prohibiting the sale of antibiotics by veterinarians and transferring the right to sell to pharmacists only. This structuring of the AMR public problem perfectly echoes Gusfield's theory since it shows how ownership and causal and political responsibilities are intimately intertwined: as the spread of resistant bacteria is the consequence of unfair veterinarian practices (i.e., their alleged conflict of interest), the only viable solution is that public authorities forbid them to sell antibiotics (i.e., separation of the prescription and delivery of veterinary drugs). At this point in time, when decoupling became the alpha and omega of the AMR problem, the veterinarians disappropriation was at its peak and their responsibility was framed in terms of guilt.

One of the most significative example of this strategy led by the human health coalition is the conference that it held in June 2011 in the French Parliament. Entitled 'how to regulate antibiotic overconsumption?', it brought representatives of doctors, pharmacists, farmers and veterinarians together with MPs and government officials. Most of the debates focused on veterinarian prescription practices and the economic model of the veterinary drug market. In the media, socialist MP Gérard Bapt, physician by training, accused veterinarians of being 'in a permanent situation of conflict of interest between prescription and sale', and invoked an ethical argument by considering that 'this accumulation should be prohibited. This would be the easiest solution"7. Pharmacists' representatives also stated that ' $98 \%$ of the

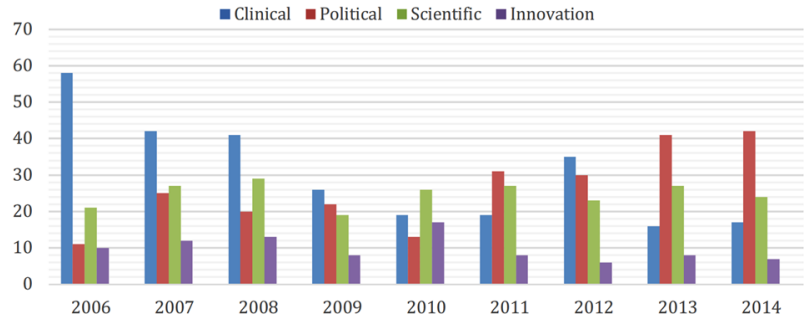

Fig. 1 Evolution of articles from La semaine vétérinaire including the words 'antibiotics' or 'antimicrobial resistance', per year and per category

prescriber's income comes from the sale of drugs. There can be no reduction in antibiotic consumption without removing this conflict of interest ${ }^{8}$. Faced with these accusations and this overpoliticization of the conflict, the veterinary profession did not have the means to build a competing framework at that time. Unable to avoid it, they could only react to the decoupling argument brandished by the human health coalition, thus validating the new frames of the AMR problem.

This phenomenon can also be observed very clearly in the veterinary press, whose editorial strategy relating to antibiotics clearly shifted between 2006 and 2014: whereas when veterinary journalists talked about antibiotics in the late 2000's, their articles essentially focused on clinical cases (recommendations for use) or on scientific studies (development of new molecules), from 2010 onwards the articles associated with the term 'antibiotics' directly referred to the political stakes of the AMR problem and the controversies on decoupling prescription and delivery of antibiotics in livestock farming (Fig. 1) ${ }^{9}$. Indeed, this framework was literally forced upon the veterinary profession which had no other choice but to reply to it. Even if they were striving to contest the causal link between AMR and veterinary drug legislation, it was nevertheless the theme of decoupling that structured political controversies and around which the conflicts over the appropriation of the public problem were being played out.

The 'political' articles show the arguments that the veterinarians, supported by farmers and the agricultural administration, tried to develop ${ }^{10}$. They focused in particular on demonstrating that situations where prescription and delivery are decoupled have not prevented the rise of resistant bacteria. Jean-Luc Angot, deputy director of the food administration (ministry of Agriculture), said: 'In France, we defend the system of prescriptiondelivery by the veterinarian, which is a security tool. For us, it is important that prescription and delivery are linked. In human medicine, the two are dissociated and there are antimicrobial resistance problems, so that's not what solved the problem'11. Defending the effectiveness of the veterinarian, his reasoning is an attempt to neutralize the arguments of doctors by underlining the persistence of resistance in human medicine, and also in veterinary medicine in countries where decoupling has been implemented for a long time. Moreover, his description of the current system as 'a security tool' suggests that the coupling of prescription and delivery is not so much the problem as the solution. The same type of argument could be found in the speech of the President of the European Veterinary Federation (FVE), Walter Winding: 'Banning the sale of medicines by veterinarians is not the solution to avoid antimicrobial resistance. [...] An approach based on training and better monitoring, as proposed in the resolution, will be more likely to achieve the desired objective than a change in distribution channels in favour of pharmacists, wholesalers or Internet merchants ${ }^{32}$. His declaration not only stresses the importance of the veterinarian's role in veterinary drug delivery, but also provides alternative solutions to the fight against AMR, such as the epidemiological monitoring of 
emerging resistance or continuing education for professionals. Pushing the argument a little further, Bernard Vallat, Director of the World Organisation for Animal Health (OIE), believes that the combination of prescription and delivery guarantees the economic viability of the profession and therefore its necessary presence on the field to control animal diseases, which also represent a danger to humans (particularly in terms of food safety and zoonosis): 'The veterinary network must be satisfactory worldwide so that the profession can fulfil its missions. There are isolated areas in the world, it is essential that the veterinarian can deliver there ${ }^{13}$.

Finally, although they denied it - and probably even because they denied it so strongly - veterinarians validated the new framing of the AMR problem, pointing to the separation of antibiotic prescription and delivery as a solution. The titles of a large number of articles in La semaine vétérinaire illustrate this unalterable link between AMR (as a problem) and decoupling (as a solution): 'Prescription-delivery assaulted by antimicrobial resistance'; 'The fight against antimicrobial resistance is the new excuse for decoupling;; 'Yes to the fight against antimicrobial resistance, no to decoupling prescription and delivery ${ }^{14}$.

Joseph Gusfield's work has shown that the construction of public problems is a process that can be analysed through its symbolic aspects (Gusfield, 1981). The definition of the problem imposed by its owners is characterized by a categorization system that designates not only the cause of the problem but also its solution and the actors who are supposed to take charge of it. In the case of AMR as defined by the human health coalition, causal responsibility refers to veterinary drug legislation (leading to antibiotic over-prescription) - in other words, an issue that was previously confined to sectorial and very poorly publicized areas. Political responsibility lies with the public authorities that the human health coalition calls upon to act to decouple the prescription and delivery of veterinary drugs. In such a framework, the responsibility of veterinarians is framed in terms of guilt since they are part of the cause of the problem and not of its solution. At that moment in time, the veterinary policy community which had owned the problem in the past was deprived of its ability to frame and govern the issue of antibiotic use in livestock, and the issue network which now owns the problem and defines both causal and political responsibilities was dominated by the human health advocacy coalition.

\section{Compromises and re-appropriation: the 'responsibility- accountability' of veterinarians}

However, this situation changed quite rapidly. Indeed, the early 2010s were marked by a veterinarian movement to re-appropriate the AMR problem. They succeeded in reversing the stigma and reappeared as part of the solution to the problem, in particular by promoting the notion of 'responsible use'. The objective was to develop a definition of the legitimate uses of antibiotics in which the veterinary profession plays an essential role. However, this was not a return to the previous state of affairs. The definition developed by the human health coalition finally required that a change in the regulation of veterinary drugs be one of the components of the AMR problem. The re-appropriation of the problem by veterinarians thus had to include several compromises because even if, as we will see, the option of decoupling the prescription and delivery of antibiotics had been rejected, changes to the regulation of veterinary drugs had to be introduced so that this notion of 'responsible use' (and of professional 'guardian' of antibiotics) could take shape. Several sequences marked this process.

The first dynamic through which this re-appropriation of the problem took place was a massive demonstration by the veterinary profession against a draft law in favour of decoupling. In 2013, the Minister of Health introduced an amendment to the French Agriculture, Food and Forestry Act, which would have separated the prescription and delivery of critically important antibiotics (CIAs) by restricting the sale of these molecules to pharmacists only. The mobilization was a major success, with almost 8000 veterinarians (about $60 \%$ of the profession) marching through the streets of Paris to oppose this measure, which was finally withdrawn. But even though this event represented a victory for the profession, forms of arrangements and a redefinition of the problem had already been visible beforehand, thus showing that veterinarians were gradually regaining control of its framing. Indeed, the draft law already concerned only CIAs and not all categories of antimicrobials.

Relatively technical and a priori not very prominent politically, this concept nevertheless relates to the same jurisdictional conflicts for the definition and appropriation of legitimate uses of antibiotics. The so-called 'critical' molecules, most often 'of the latest generation' (such as cephalosporins, fluoroquinolones or carbapenems), are those that should be safeguarded as a priority by reserving their use for human medicine-and even hospital medicine alone-in order to as far as possible delay the development of bacteria that are resistant to them. In 2007, three international organizations (WHO, OIE, FAO) thus published an initial list of these CIAs, which has since been regularly updated. Their report had no coercive power, but it gradually forced stakeholders of the AMR problem to take a stance on it. In France, this issue has been directly linked to the debates on decoupling: when the coalition of human health actors understood that a total decoupling of prescription and delivery of veterinary drugs was an unrealistic objective, the concept of CIAs made it possible to ensure that this solution continues to exist in the public debate. This option actually sounded even more credible since resistance to this kind of molecule is one of the most important issues of the AMR problem (they are 'last-resort' antibiotics). It also enabled doctors to strongly support this proposal and to make less visible the economic interest that decoupling represented for pharmacists (who would thus have regained significant market shares on the sale of veterinary drugs) $)^{15}$.

But the concept of CIAs was relatively unstable at that time as it was subject to relatively strong scientific controversies. Indeed, competing definitions of this notion coexisted, and still do. Since the lists established and updated each year by the WHO-OIEFAO trio do not have direct coercive powers, each State, agency or professional organization can produce its own categorization. This plasticity of the concept was one of the main reasons for veterinarians' refusal to a decoupling, even one limited to the 'critical' molecules: indeed, there was too high a risk that once such a measure was implemented, the list of antibiotics whose sale is prohibited to veterinarians would be extended indefinitely ${ }^{16}$. This definitional conflict around the notion of CIAs was discussed in particular by the Anses expert committee (the French Food Safety Agency) in charge of assessing the risks of AMR in animal farming between 2012 and 2014. While the Ministry of Health had made public a list of antibiotics that it considered to be critical to human health (and that should therefore be banned in veterinary medicine), this committee, composed mainly of veterinarians and animal health scientists, succeeded in questioning the legitimacy of the concept by refusing to rule on its validity.

The discussions observed within this expert committee clearly showed the discomfort that this notion (considered to be a 'trap') engendered (Dangy and Fortané, 2016). Debates were held on whether or not it was necessary to produce a list to compete with that of the Ministry of Health, which would be more appropriate to animal health issues. Some experts were in favour of this 


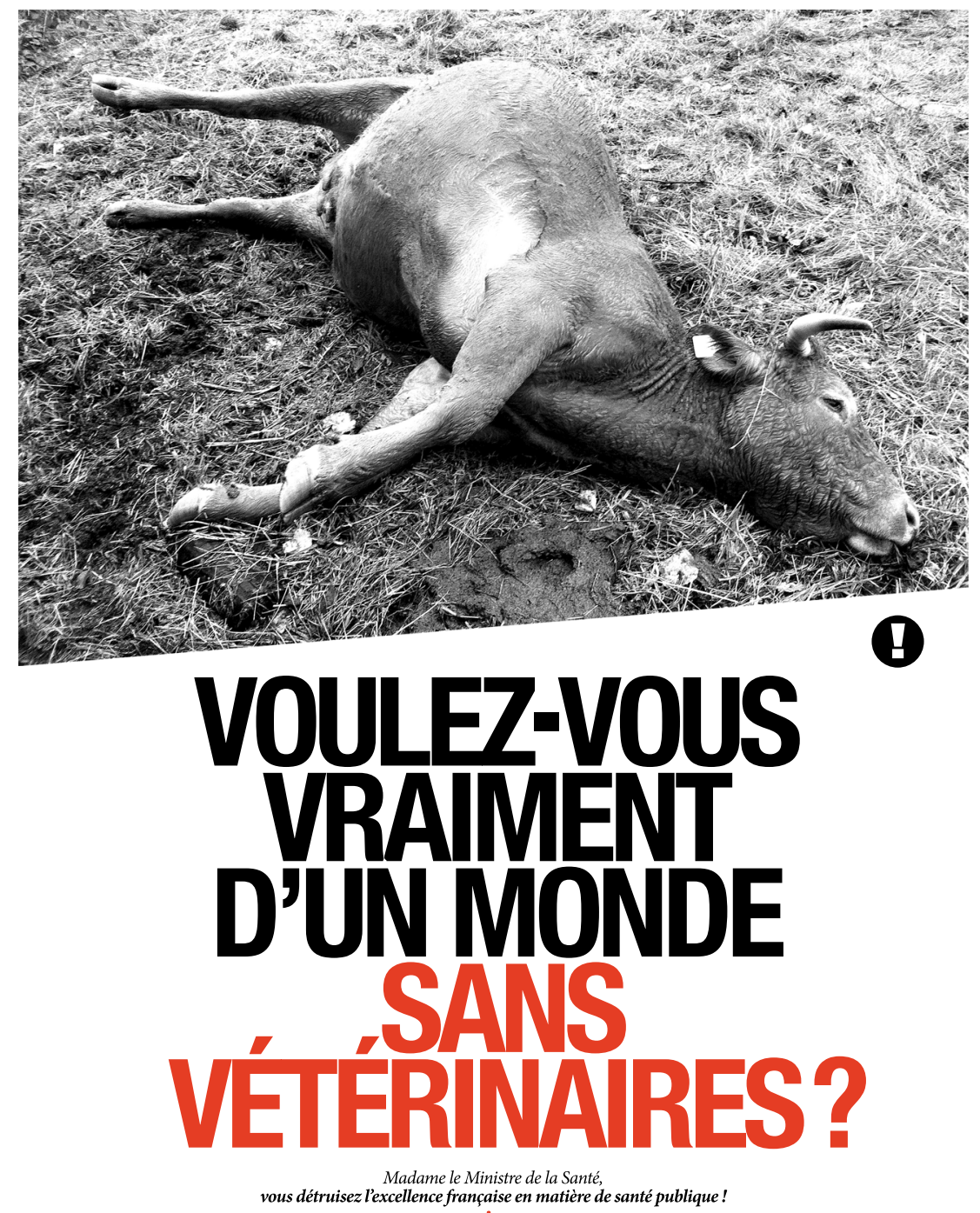

ww.stop-marisol-touraine.com

Fig. 22013 Campaign against 'decoupling'. This figure is not covered by the Creative Commons Attribution 4.0 International License. Reproduced with permission of SNVEL; copyright (C) SNVEL, all rights reserved

because they believed that the credibility of their work depended on it ('we will have no legitimacy in doctors' eyes if we do not do it'), while others were opposed on the grounds of their independence ('we will not be cutting off our nose to spite our face; we will not fall into the trap of critical antibiotics; we will not be told our roadmap by the government') ${ }^{17}$. In the end, particularly when the context of the politicization and conflictualization of the AMR problem reached its climax with the mobilization of the veterinary profession in November 2013, the Anses experts group decided not to establish its own list of CIAs and to highlight scientific arguments challenging the very point of this concept. The central idea was that a latest-generation antibiotic often has a far more controlled pharmacological action on bacterial flora and therefore generates less resistance than older molecules, particularly broad-spectrum ones (Anses, 2014).

Although this report, published in 2014 , only had an indirect impact on the withdrawal of the draft law on decoupling, it clearly shows how the veterinary profession, through its different segments (practitioners, scientists and politicians), has reappropriated the AMR problem. By challenging some of the frameworks proposed by the coalition of human health actors, veterinarians have been able to build an image where they constitute an integral part of the solution, that is to say where they are no longer responsible in terms of guilt but in terms of accountability for the judicious use of antibiotics. On a semiological level, two posters perfectly illustrate the switch between these two framings: the one from the 2013 campaign against decoupling (Fig. 2) asks 'do you really want a world without veterinarians?', while the one from the French AMR policy in 2016 (Fig. 3) states 'my vet is far more than a mere hands-on man, he is an advisor always there to prevent and vaccinate'. These two posters show how veterinarian responsibility for the AMR problem has been reframed over a period of just a few years, moving from an apocalyptic vision of a world where the guilt of veterinarians caused them to disappear, to a more utopic universe where veterinarians are accountable for the protection of animal (and therefore human) health.

In 2012, a five-year action plan (the EcoAntibio plan) to reduce the use of antibiotics in livestock farming was implemented. As in other European countries, its results were positive: an average decline of 37\% was observed between 2012 and 2017, although trends vary according to animal species and molecules. This plan 

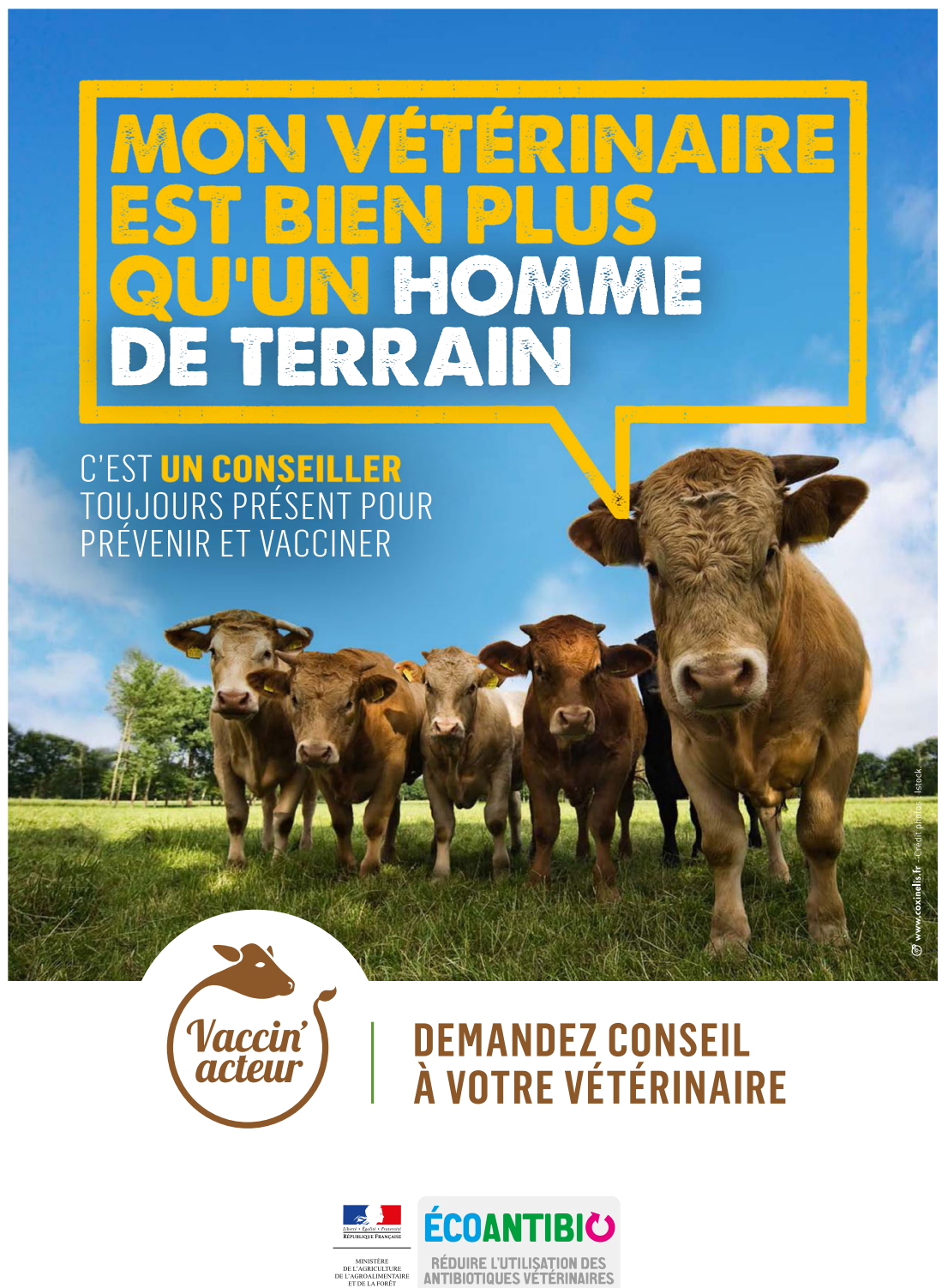

Fig. 32016 AMR policy. This figure is not covered by the Creative Commons Attribution 4.0 International License. Reproduced with permission of DGAL; copyright (c) DGAL, all rights reserved

is emblematic of the re-appropriation of the AMR problem by the veterinary profession, and the veterinary policy network in general. It is composed of a set of incentives and regulatory measures that have been gradually implemented. Some of these concern the conditions of prescription and delivery of antibiotics and show how the prior framing of decoupling has been reformulated but has nevertheless affected the current definitions of the AMR problem.

Indeed, the threat of decoupling has only been removed at the cost of compromises on the regulation of veterinary drugs, through which veterinarians have been able to demonstrate their 'responsibility-accountability'. Professional organizations have thus launched a project to update their best practice guidelines for antibiotic use, taking into account recent data on AMR risks and seeking to reduce first-line treatments to a minimum. The report of the Anses expert committee mentioned above was an important basis for this revision of the best practice guidelines. A 2016 decree also made it mandatory to perform antimicrobial susceptibility testing before any prescription of CIAs ${ }^{18}$. In other words, these molecules can no longer be used unless a bacteriological test confirms that they are the only ones that are effective in a given situation. A recent study shows that these measures have been important in the re-appropriation of the problem by veterinary practitioners, who have felt comforted in the recognition of their professional expertise now defined in the framework of evidence-based medicine and no longer of an alleged 'conflict of interest' (Bourély et al. 2018). One of the effects of this decree was to contribute to a significant drop in the prescription of CIAs, although it did not encourage any increase in the use of antibiotic susceptibility testing (which probably shows that veterinarians tended to use these antibiotics to simplify their work, even though other older molecules were still effective).

But the most emblematic measure of the EcoAntibio plan (directly enshrined in the 2014 Agriculture, Food and Forestry Act) was a major revision of the regulation of commercial rules concerning the purchase and sale of antibiotics. Known as the 'removal of the 3 Rs' (discounts, price-cuts and rebates - 'remises, rabais et ristournes' in French), this measure prohibits pharmaceutical companies from paying back-margins to veterinarians 
according to their prescription volume (a practice that had developed in the 1990s and which encouraged practitioners to achieve certain sales volumes in order to benefit from more attractive prices). This law also requires each veterinarian to sell antibiotics at the same price to all of their clients in order to prevent bilateral negotiations, again linked to sales volumes. These various measures have not been easy for the profession to accept, because beyond the transformations of the economic model of veterinary activity that they encourage, they still validate the idea that the coupling of prescription and delivery has incentivising effects on sales. But they are also a way of demonstrating the profession's awareness and its commitment to the fight against AMR, as well as providing the compromise that allows coupling to be maintained. This is exactly what the President of SIMV (Union of the veterinary pharmaceutical industry) stated: '[this measure] is the price to pay to secure the sector [and] to strengthen the current system'.

These different measures have had a significant effect not only on the framing of the AMR problem and the policy network that governs it, but also on the social structure upon which it depends. First of all, the veterinary profession and its political allies (the ministry of Agriculture and the farmers) regained power in the conflicts of definition and appropriation that were being played out in the issue network. The withdrawal of the decoupling and its replacement by a series of compromises are the result of political bargaining that show that the former veterinary policy community took back control of the AMR policy, even though one cannot say that there was a return to the previous configuration. Ownership, as well as causal and political responsibilities of the AMR problem, is now shared between a large range of actors involved in both animal and human health, but in a more balanced way. Thanks to the success of the EcoAntibio plan, the veterinary profession has been able to frame its responsibility in terms of accountability and to preserve its jurisdiction over the prescription and delivery of medicines. Veterinarians have succeeded in presenting themselves as being accountable for the definition and control of legitimate uses of antibiotics.

Secondly, this shift in the framing of the AMR problem has been made possible because veterinarians were no longer only stakeholders (whether they are part of policy community or an issue network) but also a 'public' (Dewey, 1927). Indeed, the AMR problem needs not only political entrepreneurs, but also an audience. This is exactly what the EcoAntibio measures, in particular the decree on CIAs and the ban on back-margins, helped to shape. Veterinary practitioners started to perceive the AMR problem not as a burden or a threat but as a lever that could help them to change their practices and allow their professional activity to evolve. This is for example what a veterinarian specialized in poultry production describes when he explains how he tries to manage his practice in a way that increases the use of preventive medicines, such as vaccines, compared to antibiotics. In particular, he admits that one of the key elements that made him change his mind and his strategy regarding the use of antibiotics is that he understood how economically dependent he was on antibiotic sales after EcoAntibio measures had reduced his financial margins on those sales:

For several years now, our health audits have been presented to farmers or producers' organizations with a diagram that shows the distribution of dietetic, hygiene, antibiotic, vaccines and anthelmintic products. Then we look solely at preventive and curative veterinary drugs. I put a blue mark on the preventive and a red mark on the antibiotics. The goal is to reduce the red and increase the blue. We are a team working together, farmers, technicians, organizations and veterinarians, for this purpose. We've been doing it for a while now. I think it's quite profitable in a lot of places because if you increase the blue where you also put hygiene and dietetics, everyone wins. (...) The opposite trend has been in place for many years [but] the model that interests me is that of succeeding in increasing the share of preventive medicines and reducing the share of curative medicines so that I am not dependent on these antibiotic sales. (...) We were in a relative unbalanced financial situation due to vaccines having a much lower margin than antibiotics. But today the margin for antibiotics has become very low as well and as far as we are concerned the ratio is now favourable ${ }^{19}$.

The constitution of a public that can experience a problem in one way or another is a major component of the success (or failure) of a frame (Cefai and Terzi, 2012). This is why the most significant dynamics which support the development of the 'responsibility-accountability' mindset of veterinarians certainly lies beyond public policy or media spaces. Indeed, the veterinary profession is now engaged in a broad reflection on its professional and economic model that goes beyond the AMR problem. In particular, veterinarians are highly concerned by the question of how they can support, and adapt to, the development of preventive approaches to animal health. The rethinking of veterinary services and expertise (as well as the business model it relies on) constitutes an important issue for veterinarians in many countries, such as the UK for example, where these questions have been addressed and debated for almost ten years, in the wake of the Lowe report (Lowe, 2009; Ruston et al., 2016). In France, these issues are more directly tackled by the veterinary profession because the framing of the AMR problem places veterinarians at the heart of a 'responsibility-accountability'. The development of healthy and sustainable business models is an important element of the VetFutures project led by the French Veterinary Council and the professional unions, the purpose of which is to foresee and address the future challenges that will shape tomorrow's veterinary activity (VetFuturs France, 2018). As a consequence of all these dynamics, many farm animal practices now seem to be rethinking their economic model, aware that the structure of the veterinary drug market has made their profitability too dependent on pharmaceutical sales. Various strategies for diversifying the supply of veterinary services (and their economic valuation) can be observed, showing how conflicts relating to the definition and ownership of the AMR problem can have an impact on the practices of field actors, in other words on the 'public' affected by the problem. For instance, another veterinarian specialized in poultry production explains how he is trying to develop a new care offer for his clients, one that does not rely on drug sales:

Historically in poultry farming, we don't really charge for farm visits. Overall, payment is made through drugs, which is not a bad thing for me as long as one doesn't overstep the mark. (...) But there may be unprofessional conduct, someone who might systematically place products even if there is no need. This is clearly a problem that we may have difficulty explaining. In fact that's our problem. (...) So I've been thinking for a year. Now I'm going to test a new system, a flat rate. It's brand new, I'm testing it on two or three farmers. A flat rate for veterinary follow-up, which includes farm visits and drug provision. We no longer talk about prices. (...) Right now, I don't know yet. My flat rate system may be good in theory, maybe not good if farmers... Nevertheless, in livestock farming, there are big differences in consumption. At some point the flat rate will be an 
average. Some of the farmers will find my fees a little high and the other way around, I will have farmers who may be big consumers and who might be encouraged to stay that way. So I'm not claiming victory yet, but I'm trying to find another system ${ }^{20}$.

The last two interviews show how the veterinary profession has appropriated the AMR problem not only as a political stakeholder but also as a public that is aware of its responsibilities. Of course, the point is to not view the situation through rose-tinted glasses. First of all, the study which is used here only concerns pig and poultry veterinarians. Their business model is relatively unusual compared to veterinarians working in the dairy cow sector, which represents the largest number of farm animal veterinarians (CSOV, 2018). For various historical reasons, this segment of the veterinary profession is keener to develop preventive approaches and to diversify the services it can offer farmers. Secondly, at the scale of the entire farm animal veterinarian population, business models cannot change that fast and many practices, even if they have had to implement the various AMR policy measures, probably remain dependent on medicine sales. A recent evaluation report on the EcoAntibio plan notes that thorough data on these aspects are lacking and that further research will be needed to understand how a global shift can actually be achieved (Briand et al., 2016). Nevertheless, in terms of public problem framing, it is clear that the veterinary profession has succeeded in producing a framework in which it appears as a 'guardian' of the responsible use of antibiotics. This undeniably favours the acceptation and appropriation of the changes required to develop new practices on the veterinary drug market, in particular in terms of sales and prescriptions. At the end of the day, ownership of a public problem is only really achieved when the population concerned has been constituted as a public who is experiencing and implementing the frames of this problem. In this case, farm animal veterinarians seem to be on their way to developing a virtuous responsibility for antimicrobial use, both causal and political, because they are coming to realize that they are both part of the problem and its solution. In any event, this is how the veterinary profession finally managed to frame the AMR problem and thus preserve its jurisdiction over medicines, even though the definition and control of the legitimate use of antibiotics now have to be debated and compromised within a broader configuration of actors.

\section{Conclusion}

One of the main questions that we will have to answer in the coming years is whether or not the current decline in antibiotic use in livestock farming is a sustainable trend (a reduction of $37 \%$ in antimicrobial use has been achieved under the first EcoAntibio plan). While the framing of the AMR problem in terms of the veterinarian 'responsibility-accountability' seems to have stabilized in recent years, it is clear that the possibility of demonstrating better control of antibiotic use is a major factor of its success. When this decline slows down or stabilizes, or if uses rise again for one reason or another (including an evolution of the metrics of antimicrobial resistance and antimicrobial use), it is likely that competing framings will be able to re-emerge and redefine, at least partially, the AMR problem. It is especially for this reason that the responsibility of veterinarians (and agricultural actors in general) has to be analysed beyond the knowledge, images and arguments mobilized in the public debate. It also has to be observed in the practices and strategies of the actors who decide on a daily basis whether or not to use antibiotics, and in the organisation of the veterinary drug market, the animal health market and the livestock industry which all together form the sociotechnical and socio-economic infrastructures that condition the use of antibiotics in animal farming.
Yet approaches in terms of public problems are nevertheless essential since they make it possible to analyse the balance of power and of meaning through which issues as important as that of AMR are framed and governed. It would be wrong not to see that the appropriation conflicts of this public problem are jurisdictional conflicts for the definition of the legitimate use of antibiotics, whether it is defined as responsible, judicious, prudent, rational, etc. Behind this notion of legitimate use are issues of control and access to medicines, and of course economic issues related to the incredible financial mass created by the global circulation of pharmaceuticals throughout the drug chain (production, marketing, prescription, distribution, consumption). Analysing the frames of the AMR problem therefore makes it possible to question the legitimate uses of antibiotics and their socio-technical and socio-economic infrastructures, as they have been historically established and as they are nowadays challenged.

In the case of France, the three sequences analysed in this article clearly show that the different types of veterinarian 'responsibility' are part of a system, whether desired or implemented, where professions, economic organizations or institutions are distributing antibiotic control in specific ways. Within the framework of 'responsibility-ownership', veterinarians (and the veterinary policy community) manage the drug market in a confined and therefore uncontested manner that makes them the primary, if not exclusive, beneficiaries of antibiotics. Within the framework of 'responsibility-guilt', the definition of legitimate uses of antibiotics is completely beyond their control, since the sale and use of medicines fall within the jurisdiction of an issue network dominated by other professions and institutions (pharmacists, doctors and the human health administration). Finally, within the framework of 'responsibility-accountability', the structure of the drug market seems to be moving towards a better balance where forms of external control over the legitimacy of uses exist, and where strategies are being developed to extricate antibiotics from the core of the professional and economic model of veterinary activity. All in all, one could almost hope that future AMR framings will make it possible to highlight and redefine the responsibility of actors other than veterinarians alone, who obviously remain just one link, albeit an essential one, in the global circulation of antibiotics.

Received: 10 December 2018 Accepted: 20 May 2019

Published online: 18 June 2019

\section{Notes}

1 All interviews lasted approximately $2 \mathrm{~h}$. They took place face-to-face and were recorded, transcribed and anonymised. Thematic analysis was performed in all three researches.

2 This statistic only concerns farm animal veterinarians, who represent approximately $20 \%$ of the French veterinary profession (CSOV, 2018). Small animal veterinarians and the use of antimicrobials in companion animals are outside the scope of this article as they were barely concerned by the AMR problem in the way it was framed until the mid-2010's, especially because, in volume, more than $90 \%$ of antimicrobials used in veterinary medicine are administered to farm animals (Anses, 2018).

3 Interview with a veterinarian from the pig industry, 2014 (male, 60-65 years old).

4 Riaucourt judgment of the Conseil d'État, 24 January 2007.

5 Decree 2007-596, 24 April 2007. The so-called "prescription-delivery" decree stipulates that prescription without clinical examination is possible under three conditions: an annual health audit of the farm carried out by the prescribing veterinarian, a care protocol listing the diseases against which the veterinarian may prescribe drugs (preventive or curative) without clinical examination of the animals, and a farm quota per practitioner-so that a veterinarian does not capture too many farms. Until recently, it was possible to put antibiotics on the care protocol, thus making it difficult for veterinarians to properly control the way these pharmaceuticals were actually used on the farm. 
6 In political science theory, a 'policy window' can be opened and facilitate policy change when the flow of three 'streams' are crisscrossing one another: the 'problem stream' which would put a specific problem at the heart of public concerns and controversies, the 'policy stream' which would highlight specific solutions and proposals for change and the 'politics stream' which is composed of political issues such as election results, changes of administration or interest group campaigns (Kingdon, 1984). The period between the late 2000s and the early 2010s in France was a fairly typical policy window in relation to the AMR problem.

7 "La prescription-délivrance attaquée sur l'antibiorésistance », La Semaine Vétérinaire, 2011.

8 «La prescription-délivrance attaquée sur l’antibiorésistance », La Semaine Vétérinaire, 2011,.

9 This press study was carried out with Estera Badau (Badau et al., 2019). It analyses the treatment of antibiotic and AMR issues in 822 articles (where these two terms occurred) in the main veterinary professional journal in France: La semaine vétérinaire. All the quotes from this section are extracted from articles of this journal.

10 It is also interesting to have a look at how the way antibiotics mentioned in clinical articles changed over the years. It shows how, during this highly controversial and politically sensitive period, the perception of antibiotics shifted within the veterinary profession. At the beginning of the analysed period, linguistic expressions containing the words 'antibiotics' or 'antibiotic therapy' are often followed by expressions such as 'first intention', 'extended treatment', 'necessary', 'broad spectrum' and the use of antibiotics is often qualified as 'the only answer', 'imperative', 'essential' or 'systemic'. From 2009 onwards, the use of antibiotics instead becomes 'recommended' or 'preferable' and to be applied according to the results of antibiotic susceptibility tests. From 2011 onwards, antibiotic therapy is expected to be 'reasonable, rational and adapted to bacteriological samplings'. The notions of 'responsible', 'judicious' or 'appropriate' use of antibiotics also appear, whereas these terms had not been used before: they are indeed characteristic of the public debates of that period and of the AMR policy the implementation of which began in 2012.

11 "L'amendement contre le droit de vente des médicaments par les vétérinaires est écarté », La Semaine Vétérinaire, 2011.

12 "L’amendement contre le droit de vente des médicaments par les vétérinaires est écarté », La Semaine Vétérinaire, 2011.

13 "Une démarche impérativement mondiale, selon l'OIE contre l'antibiorésistance ", La Semaine Vétérinaire, 2012.

14 These examples were extracted from the political subcorpus with Lexico3 (a lexical occurrence software), in order to observe the association of the two terms 'antimicrobial resistance' and 'decoupling'.

15 The veterinary press has also helped to make this economic interest of pharmacists visible in order to make the decoupling proposal less credible. For example: 'Antibiotic resistance: pharmacists in need of turnover, public authorities worried about back margins insufficiently ethical for their taste' ('Fêlure, fissure, fracture', $\mathrm{La}$ Semaine Vétérinaire, 2012).

16 Debates on colistin are a good example of this situation. It is an old molecule which has rarely been used in human medicine since the 1970 's but which constitutes a key element of the veterinary pharmacopoeia. As people has realized that colistin remains effective against several current multi-resistant bacteria, some actors now consider that it should be classified as a CIA and reserved for human medicine. Although the veterinary community protested, colistin was added to the WHO CIAs list in 2017.

17 These quotes come from my field notebooks containing the ethnographic observations I made of this expert committee between 2012 and 2014. These are sentences spoken by the experts during meetings.

18 Decree n²016-317, 16 March 2016.

19 Interview with a veterinarian from the poultry industry, 2015 (male, 35-40 years old). 20 Interview with a veterinarian from the poultry industry, 2015 (male, 45-50 years old).

\section{References}

Abbott A (1986) Jurisdictional conflicts: A new approach to the development of the legal professions. Law Soc Inq 11(2):1987-224

Abbott A (1988) The system of professions: an essay of the division of expert labor. The University of Chicago Press, Chicago

Abbott A (2005) Linked ecologies: States and universities as environments for professions. Sociol Theory 23(3):246-274

Anses (2014) Évaluation des risques d'émergence d'antibiorésistances liées aux modes d'utilisation des antibiotiques dans le domaine de la santé animale. Avis de l'Anses, rapport d'expertise collective, Maisons-Alfort

Anses (2018) Suivi des ventes de médicaments vétérinaires contenant des antibiotiques en 2017 en France. Anses-ANMV, Maisons-Alfort

Badau E, Fortané N, Arquembourg J (2019) Les appropriations de l'antibiorésistance en France: la carrière d'un problème public au sein de la presse vétérinaire (2006-2014). In: Bernardin S (ed) Croisades privées et problèmes publics. L'héritage sociologique de Joseph Gusfield. Presses Universitaires de Rennes, Rennes
Baumgartner F, Jones B (1993) Agendas and instability in American politics. University of Chicago Press, Chicago

Benford R, Snow D (2000) Framing processes and social movements: an overview and assessment. Annu Rev Sociol 26:611-639

Berdah D (2010) La vaccination des bovidés contre la tuberculose en France, 19211963: entre modèle épistémique et alternative à l'abattage. Rev d'Etudes en Agric et Environ 9(4):393-415

Berdah D (2012) Entre scientifisation et travail de frontières: les transformations des savoirs vétérinaires en France, xviii $^{\mathrm{e}}$-xix $^{\mathrm{e}}$ siècles. Rev d'Hist Mod et Contemp 59(4):51-96

Begemann S, Perkins E, Van Hoyweghen I, Christley R, Watkins F (2018) How political cultures produce different antibiotic policies in agriculture: a historical comparative case study between the UK and Sweden. Sociol Rural 58 (4):765-785

Bonnaud L, Fortané N (2016) Au-delà des crises de santé animale. Pour une sociologie de l'action publique vétérinaire. Gouv et Action Publique 5(3):131-140

Bonnaud L, Fortané N (2018) L'État sanitaire de la profession vétérinaire. Action publique et régulation de l'activité professionnelle. Sociologies 9(3):253-342

Bourély C, Fortané N, Calavas D, Leblond A, Gay E (2018) Why do veterinarians ask for antimicrobial susceptibility testing? A qualitative study exploring determinants and evaluating the impact of antibiotic reduction policy. Prev Vet Med 159(1):123-134

Briand P, Dupuy C, Parle L (2016) Le plan EcoAntibio 2012-2016. Évaluation et recommandations pour le plan suivant. CGAAER, Paris

Bud R (2007) Penicillin: triumph and tragedy. Oxford University Press, Oxford

Buffetaut Y, Gourlet-Fleury S (2001) Vétérinaires et paysans au xxe siècle. Ysec Editions, Louviers

Cefaï D, Terzi C (2012) L'expérience des problèmes publics. Perspectives pragmatistes. EHESS, Paris

Crémieux AC (2016) Brève histoire du plan antibiotiques du ministère de la Santé en France. Quest de Commun 29:87-93

CSOV (2018) Atlas démographique de la profession vétérinaire. CSOV, Paris

Dahan M, Hanotaux P, Durand F, Liebert F (2013) Encadrement des pratiques commerciales pouvant influencer la prescription des antibiotiques vétérinaires. IGF/IGAS/CGAAER, Paris

Dangy L, Fortané N (2016) Les frontières floues de l'expertise. Le cas de la normalisation du médicament vétérinaire. Les Cah Droit, Sci et Technol 6:103-121

Delomenie P, Guibe J, Lacaze D, Manfredi A (2002) Rapport sur la distribution au détail du médicament vétérinaire. Ministère de l'Emploi et de la solidarité / Ministère de l'Agriculture, Paris

Dewey J (1927) The public and its problem. Holt and Company, New York, NY

Finlay MR, Marcus AI (2016) Consumerist terrorists: battles over agricultural antibiotics in the United States and Western Europe. Agric Hist 90:146-172

Gilbert C, Henry E (2012) Defining social problems: Tensions between discreet compromise and publicity. Rev Française de Sociol 53(1):35-59

Guillemot P, Vandaële E (2009) L'arrêt Riaucourt et ses effets. Bull de l'Académie Vétérinaire de Fr 162(2):171-180

Gusfield J (1981) The culture of public problems: drinking-driving and the symbolic order. University of Chicago Press, Chicago

Hall P (1993) Policy paradigms, social learning, and the state: the case of economic policymaking in Britain. Comp Polit 25(3):275-96

Hubscher R (1999) Les Maîtres des bêtes. Les vétérinaires dans la société française, xviiie-xxe siècle. Editions Odile Jacob, Paris

Kingdon J (1984) Agendas, alternatives, and public policies. Little, Brown, Boston

Kirchhelle K (2018) Pharming animals: a global history of antibiotics in food production (1935-2017). Palgrave Commun 4:article number: 96

Lowe P (2009) Unlocking potential: a report on veterinary expertise in food animal production. A Report to the Vets and Veterinary Services Steering Group. Report to Department for Environment, Food and Rural Affairs, London

Marsh D, Rhodes R (eds) (1992) Policy networks in British Government. The Clarendon Press, Oxford

Ollivier N (2013) The end of the french model for animal health? A sociological analysis of the Bluetongue Vaccination Campaign (2007-2009). Sociol Rural 53(4):496-514

Podolsky S (2015) The antibiotic era: Reform, resistance, and the pursuit of a rational therapeutics. Johns Hopkins University Press, Baltimore

Podolsky S (2018) The evolving response to antibiotic resistance (1945-2018). Palgrave Commun 4:article number: 124

Rochefort and Cobb (eds) (1994) The politics of problem definition. Shaping the policy agenda. University Press of Kansas: Lawrence

Ruston A, Shortall O, Green M, Brennan M, Wapenaar W, Kaler J (2016) Challenges facing the farm animal veterinary profession in England: a qualitative study of veterinarians' perceptions and responses. Prev Vet Med 127:84-93

Sabatier P (1988) An advocacy coalition framework of policy change and the role of policy-oriented learning therein. Policy Sci 21(2-3):129-068

Sabatier P, Jenkins-Smith H (eds) (1993) Policy change and learning: an advocacy coalition approach. Westview Press: Boulder, CO, USA 
Snow D, Burke E, Worden S, Benford R (1986) Frame alignment processes, microbilization, and movement participation. Am Sociol Rev 51(4):464-81

Snow D, Benford R (1988) Ideology, frame resonance and participant mobilization. Int Soc Mov Res 1:197-217

Stone D (1989) Causal stories and the formation of policy agendas. Political Sci Q 104(2):281-300

VetFuturs France (2018) Le livre bleu: comprendre et anticiper les mutations de la profession vétérinaire. SNVEL/CSOV, Paris

Wilkinson K, Lowe P, Donaldson A (2010) Beyond policy networks: policy framing and the politics of expertise in the 2011 Foot-and-mouth disease crisis. Public Adm 88(2):331-345

\section{Additional information}

Competing interests: The author declares no competing interests.

Reprints and permission information is available online at http://www.nature.com/ reprints
Publisher's note: Springer Nature remains neutral with regard to jurisdictional claims in published maps and institutional affiliations.

\section{(c) (i)}

Open Access This article is licensed under a Creative Commons Attribution 4.0 International License, which permits use, sharing, adaptation, distribution and reproduction in any medium or format, as long as you give appropriate credit to the original author(s) and the source, provide a link to the Creative Commons license, and indicate if changes were made. The images or other third party material in this article are included in the article's Creative Commons license, unless indicated otherwise in a credit line to the material. If material is not included in the article's Creative Commons license and your intended use is not permitted by statutory regulation or exceeds the permitted use, you will need to obtain permission directly from the copyright holder. To view a copy of this license, visit http://creativecommons.org/ licenses/by/4.0/.

(C) The Author(s) 2019 